\title{
O SISTEMA MULTIPORTAS NO CÓDIGO PROCESSUAL CIVIL DE 2015: A MEDIAÇÃO COMO ALTERNATIVA DE AUTOCOMPOSIÇÃO DO CONFLITO
}

THE MULTIPORT SYSTEM IN THE CIVIL PROCEDURAL CODE OF 2015: MEDIATION AS AN ALTERNATIVE OF SELF-CONTROL OF THE CONFLICT

\section{Lorena Gonçalves Lima Rocha ${ }^{1}$}

ISSUE DOI: $10.21207 / 1983.4225 .435$

\section{RESUMO}

Os conflitos fazem parte da nossa rotina, não há como desvencilhar o trato das relações humanas sem atentar que a realidade de cada indivíduo difere um do outro física e culturalmente, possuindo cada um uma abordagem diferente sobre suas concepções. Nestas diferenças irá residir a capacidade de cada um em saber lidar com as divergências inatas ao homem e, na sua ausência observaremos o estopim de um contexto conflituoso. Na busca pela resolução dos conflitos iremos encontrar na mediação um método pa- 
cifico e eficaz de resolução de conflitos por meio de um método de autocomposição. O presente trabalho científico tem por escopo a abordagem da mediação como alternativa à apreciação jurisdicional do conflito de interesses, seguindo ainda pela apreciação do "Sistema Multiportas" no âmbito jurídico, e por fim a apresentação dos fatos que visam dar ao instituto eficácia elevando o mesmo ao status de política pública.

Palavras-chave: Mediação. Conciliação. Sistema Multiportas.

\section{ABSTRACT}

The conflicts are part of our routine, there's no way to extricate the deal of human relationships without heed to the reality of each individual differs from each other physically and culturally, with each different approach about their conceptions. These differences will reside the ability of each to know deal with innate differences to the man, and in his absence we will look at the fuse of a confrontational context. In the search for resolution of conflicts we will find mediation and conciliation in a peaceful and effective alternative for conflict resolution by means of a autocomposição method. The present work aims to scientific approach of conciliation and mediation as an alternative to judicial review of conflict of interest, following the assessment of the "Multi-port System" under law, and finally the presentation of facts which aim to give the Institute effectively raising it to the status of public policy.

Keywords: Mediation. Conciliation. Multi-port System.

\section{INTRODUÇÃO}

A busca por meios eficazes para solução dos conflitos não é uma novidade da sociedade moderna. Há tempos o homem vem buscado métodos capazes de provê-lo em face dos dissídios oriundos das relações humanas. Dentro desses anseios podemos verificar a mediação como alternativa eficaz para a resolução de conflitos. 
A mediação vem cada vez mais ganhando espaço no cenário jurídico brasileiro como alternativa eficientemente capaz de solucionar os conflitos que viessem a existir dentro de determinada relação jurídica. Como método de autocomposição de resolução de conflito, o referido instituto irá pautar-se na busca pela solução do conflito de uma forma pacífica e capaz de trazer as partes um viés satisfatório, fator este incapaz de ser obtido no judiciário, tendo em vista o caráter de vencedor e perdedor imposto às partes litigiosas.

O Código de Processo Civil de 2015 é um grande incentivador dos métodos alternativos de solução de conflitos, dentre eles a mediação, trazendo em seu texto diversos dispositivos que abordam o tema, inclusive um capítulo inteiro dedicado à figura do mediador e do conciliador. Além do mais, os parágrafos do artigo $3^{\circ}$ nos traz uma abordagem clara e expressa do incentivo dado pelo legislador ao uso de outras formas de composição, é o Sistema Multiportas.

Busca-se, dessa forma, fazer uma análise conceitual sobre a mediação, explicando-a e apresentado especificações quanto as suas características, de modo a trazer uma compreensão sobre o tema estudado e suas implicações jurídicas.

\section{DA MEDIAÇÃO}

\subsection{CONCEITO}

O termo mediação origina da palavra mediare que em latim significa mediar, ou seja, intervir, sendo esse o seu principal papel, qual seja, a intervenção no conflito como meio de solução do impasse entre as partes. Busca-se na mediação produzir um acordo cuja solução será sugerida e não imposta às partes. A mediação exerce uma função ativa de modo que um terceiro vem a interceder na tentativa de reconciliar as partes conflitantes por meio de um acordo extrajudicial. 


\section{Para Ana Karine Pessoa Cavalcante Miranda $^{2}$ a mediação poderá ser conceituada como:}

Um meio consensual e não adversarial de resolução de conflitos, no qual as partes escolhem um terceiro imparcial e capacitado, no caso o mediador, que servirá de canal de diálogo e pacificador entre as partes, não interferindo no mérito das decisões.

Do mesmo modo entende João Roberto da Silva ${ }^{3}$ ao dispor que: "a mediação é uma técnica não adversarial, em que um terceiro (mediador) neutro e imparcial, auxilia as partes a entenderem seus reais conflitos, buscarem seus verdadeiros interesses, por intermédio de uma negociação cooperativa na procura de melhores e mais criativas soluções".

Logo, extrai-se que na mediação as partes são as protagonistas do conflito, ou seja, cabe a elas o poder de decisão, sendo papel do mediador apenas o de direcionar, levar os participantes a construírem seus próprios acordos. Em razão disto, entende-se que a mediação é um método autocompositivo que deve ser utilizado quando entre as partes em conflito já exista uma relação jurídica anterior.

Diferente do que ocorre na conciliação, outro método de composição do conflito, onde não há entre as partes uma relação jurídica préexistente, tendo então o conciliador um papel mais ativo na busca da resolução do conflito, podendo este, inclusive, propor um acordo que acredite ser benéfico para os conflitantes, fato este que não ocorrerá na mediação.

Podemos compreender assim que a mediação atua como um método capaz de resolver o conflito por intermédio da ajuda de um terceiro que não atuará diretamente no caso, mas sim irá conduzir os conflitantes

\footnotetext{
${ }^{2}$ MIRANDA, Ana Karine Pessoa Cavalcante. Estudos sobre a efetivação do direito na atualidade - A cidadania em debate - Mediação de conflitos. ARTIGO: A mediação de conflitos como instrumento de acesso ã justiça, inclusão social e pacificação, p.8.

${ }^{3}$ SILVA, João Roberto da. Arbitragem e mediação - aspectos gerais da Lei 9.037/1996. apud. GALVÃO, Cibele Ramos. A mediação como instrumento consensual nos conflitos familiares. In: FEMPAR - fundação escola do Ministério Público do Paraná, Curitiba, publicado em: 19 ago 2010. Disponível em:

$<$ http://www.femparpr.org.br/artigos/upload_artigos/cibele\%20ramos\%20galvao.pdf $>$. Acesso em fev. 2014.
} 
para que estes consigam por si só através do diálogo solucionarem a contenda a que deram causa. O mediador como interventor não irá impor as partes a solução que acredita ser mais conveniente, ele não possui esse papel.

Entende-se assim que a mediação é um método consensual e não adversarial, ela busca dar aos mediandos uma voz ativa para que estes sejam os verdadeiros conciliadores do conflito, para que juntos possam encontrar uma solução benéfica para ambos evitando que as partes de digladiem na busca de uma resposta que indique um certo/errado ou um vencedor/perdedor da contenda.

\subsection{CARACTERÍSTICAS}

A instituição da mediação requer a conjugação de diversas características próprias que a evidenciam como alternativa eficaz para a busca da solução do conflito. Leonardo Pessoa de Aguiar ${ }^{4}$ nos mostra que a mediação seguirá as características da privacidade, economia financeira e de tempo, reaproximação das partes, voluntariedade, autonomia das decisões e eficácia do cumprimento dos acordos firmados.

Em regra geral a mediação irá garantir o respeito pela vida privada, logo o processo de mediação terá acesso restrito as partes e seus assessores, na existência destes, ficando a possibilidade de publicização a cargo da vontade dos participantes do instituto ${ }^{5}$, sendo assim, as discussões ocorridas durante a mediação são sigilosas e não poderão ser utilizadas posteriormente.

A confidencialidade do processo de mediação também deverá ser garantida pelas partes que deverão manter em segredo as sessões das quais participarem e também assumindo o compromisso de renunciarem ao mediador como testemunha em caso de um futuro processo judicial no qual o objeto da mediação seja objeto da contenda judicial ${ }^{6}$. No mesmo sentido

\footnotetext{
${ }^{4}$ AGUIAR, Leonardo Pessoa. A mediação no âmbito familiar. In: JurisWay, enviando em 05 jun 2010. Disponível em: < http://www.jurisway.org.br/v2/dhall.asp?id_dh=4121>. Acesso em: fev 2014.

${ }^{5}$ Ibidem.

${ }^{6}$ MORI, Amaury Haruo. Princípios gerais aplicáveis ao processo de mediação e conciliação. In. Revista do Tribunal do Trabalho da 9. Região, 1976, v. 34, n. 63, p. 117-156, jul./dez., 2009.
} 
não poderá o mediador atuar como perito nesses litígios. Tudo com a finalidade de garantir o sigilo da mediação.

Haverá exceção caso seja observada a existência de interesse público, somente nessa hipótese o processo de mediação deverá ser publicizado independente da vontade dos envolvidos. Ainda nesse sentido, as informações que não sejam de caráter pessoal ou que possam representar uma ameaça à integridade física, psíquica de outrem também não estarão sujeitas a confidencialidade ${ }^{7}$. Logo, entendesse que na mediação os atos não serão públicos conforme ocorre no processo judicial.

A reaproximação das partes diz respeito ao consenso objeto da mediação. Em razão do diálogo evolvido no instituto os litigantes buscam uma solução que beneficie a ambos os envolvidos evitando assim, as empatias provenientes dos ganhos e perdas judiciais. Já a voluntariedade considera a opção das partes de se submeterem ou não ao processo mediatório da mesma forma que as mesmas podem optar por continuarem nele até o fim ou desistirem. Percebe-se que tudo depende da livre vontade dos conflitantes, não há na mediação uma obrigatoriedade, não pode ser imposta, ela é voluntária e espontânea para aqueles que dela querem desfrutar.

As partes possuirão autonomia em suas decisões, tendo em vista que cabe somente a elas a busca pela solução do conflito e por assim eleger em comum acordo aquela que será mais satisfatória para o conjunto. Diferente do modo judicial de resolução de conflitos, na mediação a solução não será sugerida, tão pouco será imposta por um juiz, cabe somente aos litigantes a concretização do acordo que será melhor para a resolução do embate ${ }^{8}$.

Compete somente às partes a busca pela mediação e escolha da solução que vise o benefício de todos, não havendo imposições, mas tão somente uma autonomia de vontade. Por assim, podemos concluir que a quantidade de cumprimento dos acordos firmados será de um quantum maior do que os observados quando de uma decisão imposta, haja vista que será levado em consideração que as soluções provenientes da mediação serão escolhidas dentro das possibilidades de cada litigante.

\footnotetext{
${ }^{7}$ MORI, Amaury Haruo. Princípios gerais aplicáveis ao processo de mediação e conciliação. In. Revista do Tribunal do Trabalho da 9. Região, 1976, v. 34, n. 63, p. 117-156, jul./dez., 2009.

${ }^{8}$ AGUIAR, Leonardo Pessoa. A mediação no âmbito familiar. In: JurisWay, enviando em 05 jun 2010. Disponível em: < http://www.jurisway.org.br/v2/dhall.asp?id_dh=4121>. Acesso em: fev 2014.
} 
Deve-se ainda levar em consideração que a mediação será dotada de um caráter eminentemente pessoal ${ }^{9}$. Somente as partes conflitantes poderão participar do processo, devendo se fazer presente pessoalmente em cada sessão, não sendo admitida a sua representação.

Destarte, cumpre expor, que as partes poderão ser acompanhadas por seus respectivos advogados que exercerão a função de assessores ou consultores durante o processo de mediação.

Por fim, podemos observar que as características que regem o instituto da mediação podem também ser vistas como princípios basilares que a norteiam, sendo por diversas vezes possível encontrar entre os autores uma interseção nesses dois aspectos da mediação.

\subsection{MEDIAÇÃO, CONCILIAÇÃO E ARBITRAGEM: DIFERENÇAS}

O processo de mediação é apenas mais um dentre os variados métodos não-adversariais de resolução de conflito, onde ainda podemos destacar a conciliação e a arbitragem. Em face dessa diversidade de métodos muitos doutrinadores se preocuparam em distinguir cada um dos institutos entre si quanto a sua aplicabilidade ou modo de execução, sendo mais eficaz para esse estudo diferenciar a mediação dos demais.

Neste ínterim, por tudo que já foi estudado, a mediação irá se diferenciar da arbitragem no sentido de que nesta não há um favorecimento ao diálogo entre as partes. Na arbitragem as partes conflitantes irão escolher um terceiro imparcial e neutro que irá tomar uma decisão quanto ao conflito, devendo esta ser cumprida pelas partes, sendo dotada de eficácia de sentença judicial e por assim, configurando um título executivo judicial.

\footnotetext{
${ }^{9}$ CENCI, Andreia Katia. Mediação familiar: um método de facilitação para resolução de conflitos sem a demora dos judiciários, com benefícios para ambas às partes. Disponível em:

<http://www.egov.ufsc.br/portal/conteudo/media\%C3\%A7\%C3\%A3o-familiarum-m\%C3\%A9todo-de-facilita\%C3\%A7\%C3\%A3o-para-resolu\%C3\%A7\%C3\%A3o-de-conflitos-sem-demora-dos-judic>. Acesso em fev 2014.
} 
No que diz respeito às diferenças quanto ao instituto da conciliação devemos nos reportar às ideias de Haim Grunspun ${ }^{10}$, onde o autor nos mostra que na conciliação, o conciliador irá conduzir o processo na direção do acordo, de modo a opinar e propor soluções para o conflito, fato este que não ocorre na mediação onde o mediador será imparcial não opinando no feito.

Assim, na conciliação observamos uma postura ativa por parte do conciliador que intervém na conciliação e ainda opina sobre o acordo que entende ser mais benéfico. Na mediação isso não ocorre, o mediador só intervirá na mediação para evitar que haja novos desentendimentos ou se entender que as partes não estão aptas a encontrarem um acordo, fato este que o permitirá a dar fim ao processo mediatório. Fora isso o mediador deverá se manter como um espectador ouvir os conflitantes e apenas ajudálos no alcance do acordo perfeito.

O CPC de 2015 identifica as diferenças entre a mediação e conciliação no que corresponde a pré-existência ou não de uma relação jurídica entre as partes. Assim, de um modo preferencial, o conciliador atuará nos casos em que não exista um vínculo anterior entre as partes, enquanto o mediador atuará nos casos em que haja o referido vínculo, conforme observamos nos parágrafos $2^{\circ}$ e $3^{\circ}$ do art. 165 da norma.

Art. $165, \S 20 \quad \mathrm{O}$ conciliador, que atuará preferencialmente nos casos em que não houver vínculo anterior entre as partes, poderá sugerir soluções para o litígio, sendo vedada a utilização de qualquer tipo de constrangimento ou intimidação para que as partes conciliem.

$\S 30$ O mediador, que atuará preferencialmente nos casos em que houver vínculo anterior entre as partes, auxiliará aos interessados a compreender as questões e os interesses em conflito, de modo que eles possam, pelo restabelecimento da comunicação, identificar, por si próprios, soluções consensuais que gerem benefícios mútuos.

\footnotetext{
${ }^{10}$ GRUSPUN, Hain. Mediação familiar: o mediador e a separação de casais com filhos. São Paulo: Ltr, 2000. p. 34.
} 


\section{A MEDIAÇÃO COMO INSTRUMENTO DE EFICÁCIA NA RESOLUÇÃO DOS CONFLITOS}

\subsection{DAS VANTAGENS E EFICÁCIA DA MEDIAÇÃO}

A Emenda Constitucional n. 45, promulgada em 2004, incluiu ao texto do art. $5^{\circ}$ da Constituição Federal, o qual elenca os direitos fundamentais do cidadão, o inciso LXXVIII que contém o enunciado a seguir: "A todos, no âmbito do judicial e administrativo, são assegurados a razoável duração do processo e os meios que garantam a celeridade de sua tramitação". Conjugado a isso se tem o art. 226, do mesmo dispositivo legal no qual assegura à família uma "especial proteção do Estado".

Esses dois textos normativos quando associados fazem referência ao direito subjetivo que as partes possuem de uma efetiva prestação jurisdicional nos seus litígios, devendo o estado assegurar que os mesmos serão resolvidos em tempo razoável sem que haja comprometimento da relação jurídica pré-existente.

A mediação atuará de forma a favorecer e promover o alcance dos objetivos previstos na legislação constitucional e dentro desta perspectiva irá atuar no resgate do ser humano, que busca em seu íntimo a concretização de seus anseios. Assim, a possibilidade de ter por atendida tanto as expectativas que digam respeito ao lado emocional quanto ao patrimonial do conflitante, revelará uma das vantagens da mediação, que permitirá que a pessoa distinga o lado afetivo e o lado econômico da situação.

Os benefícios da mediação são incontáveis, dentre os métodos de resolução de conflito, ela será o meio mais eficaz para a resolução dos litígios, principalmente os de ordem familiar, tendo em vista sua capacidade de reaproximação das partes através da construção do diálogo para que os mediandos encontrem a razão real do conflito.

Das vantagens que podem ser imputadas à mediação, Cibele Ramos Galvão ${ }^{11}$ traz a celeridade como uma delas. A resolução do conflito

${ }^{11}$ GALVÃO, Cibele Ramos. A mediação como instrumento consensual nos conflitos familiares. In: FEMPAR, Curitiba, publicado em: 19 ago 2010. Disponível em:

$<\mathrm{http} / / / \mathrm{www}$. femparpr.org.br/artigos/upload_artigos/cibele\%20ramos\%20galvao.pdf $>$. Acesso em fev. 2014. 
em um tempo adequado é uma das principais características deste método resolutivo.

Além da eficiência temporal, a mediação contará a seu favor que o tempo desprendido em seu processo valerá mais ainda quando comparado com a eficiência de seu trabalho. Em nenhum outro método de resolução de conflitos as partes poderão alcançar um nível mútuo de satisfação quanto ao alcançado na mediação, visto que esta valoriza primordialmente o acordo benéfico para ambas as partes conflitantes não sendo admitido a caracterização de uma figura mais favorecida com o processo.

Ainda podemos observar que por meio da mediação há uma considerável redução do custo financeiro. O custo da mediação é muito inferior ao custo do processo judicial ${ }^{12}$. Na causa que tramita no judiciário há uma diversidade de gastos, tais como com honorários de advogado, custas processuais e perícias. Por outro lado, na mediação se poupariam diversos desses gastos, sobretudo com diligências, perícias e outras provas, haja vista não serem relevantes para se alcançar uma autocomposição. Além de que a celeridade na duração processual faz com que o conflito seja resolvido em tempo inferior ao do processual, ocasionando uma diminuição do custo indireto.

Dentre outras vantagens da mediação, a resolução do problema e não do processo é uma das mais relevantes a este tipo de procedimento. A mediação ao contrário do trâmite processual não irá delimitar o assunto que irá ser abordado àquele apresentado na petição inicial. $\mathrm{O}$ mediador deve provocar as partes para que expressem seus sentimentos e assim seja possível encontrar a real causa que deu origem ao conflito. $\mathrm{Na}$ mediação, busca-se a cura do litígio e não apenas o arquivamento de uma contenda.

Neemias Marinetti Prudente ${ }^{13}$ segue este mesmo entendimento, quando se refere à mediação no âmbito familiar como um método para pôr

${ }^{12}$ CALMON, Petrônio. Fundamentos da mediação e da conciliação. apud SILVA, Sérgio Ricardo Desiderio da. A mediação como método de resolução de conflitos relacionados à gestão de recursos hídricos no Distrito Federal. In:Âmbito Jurídico, Rio Grande, XII, n. 66, jul 2009. Disponível em: <http://www.ambito-juridico.com.br/site/index.php?n_link=revista_artigos_leitura\&artigo_id=6429>. Acesso em mar 2014.

${ }^{13}$ PRUDENTE, Neemias Moretti. A mediação e os conflitos familiares. In: Âmbito Jurídico, Rio Grande, XI, n. 52, abr 2008. Disponível em:

$<$ http://www.ambitojuridico.com.br/site/index.php?n_link=revista_artigos_leitura\&artigo_id=2536>. Acesso em abr 2014. 
fim ao conflito real, e não ao conflito aparente, pois assim está sendo solucionado o verdadeiro problema.

Ademais, a resolução do problema real ainda traz como consequência a apreciação de mais duas vantagens da mediação, quais sejam, a prevenção na formação de novos conflitos e a prevenção da reincidência do conflito trabalhado. O método autocompositivo da mediação tende a fazer com que, após o processo, os envolvidos não somente se vejam ressarcidos dos prejuízos sofridos, mas também sintam que aquele conflito pelo qual passaram esteja superado, satisfazendo tanto a lide colocada em discussão como eventuais conflitos sociais subjacentes.

Ainda assim, vale lembrar mais uma vantagem da mediação que é a eficácia no cumprimento dos acordos firmados, visto que sendo o acordo elaborado conjuntamente por ambas as partes, e sendo estas duas beneficiadas igualmente, o acordo então estará dentro das possibilidades dos mediandos.

A visão de que os conflitantes são os verdadeiros construtores do acordo garante que ambas as partes saiam beneficiadas o que vem a garantir um viés positivo da mediação já que todos saem do conflito com a sensação de terem alcançado o melhor resultado. Nessa lógica de autonomia da vontade das partes, ou seja, de que elas são os responsáveis pela resolução do conflito, Lília Maia de Moraes Sales ${ }^{14}$ entende que: "a observância do acordo independe de qualquer força executiva, visto que, tendo sido o conflito tratado entre as partes e por elas solucionado, o seu cumprimento é consequência natural".

A autora quis assim dizer que na mediação não haverá necessidade de tramites de caráter executório visto que, sendo o acordo discutido e realizado entre as partes de modo a beneficiar ambas igualmente, a probabilidade de não cumprimento do mesmo será rara. Na mediação as partes trabalharão para encontrarem um ponto que seja passível de ser cumprido por todos os envolvidos e que ainda satisfaça as expectativas comuns aos conflitantes.

Não há como enumerar cada uma das vantagens da mediação, o tempo desprendido para tal feito seria absurdo e ainda estaríamos passíveis

${ }^{14}$ SALES, Lília Maia de Moraes. Justiça e mediação de conflitos. Apud Rosa, Conrado Paulino. In: Âmbito Jurídico, Rio Grande, XII, n. 64, maio 2009. Disponível em:

$<$ http://www.ambito-juridico.com.br/site/index.php?n_link=revista_artigos_leitura\&artigo_id=6116> . Acesso em fev 2014. 
a esquecer de alguma característica primordial ao método. Cabe-nos apenas elucidar pontos específicos da matéria a ponto de podermos demonstrar que em cada uma das vantagens apresentadas nesse estudo, observamos a característica comum da tentativa de fazer com que aqueles que se prestam ao método sintam-se confiantes diante de sua metodologia. Cada parte da mediação visa unicamente fazer com que os mediados sintam-se beneficiados pelo projeto, e nunca ameaçados.

\subsection{A MEDIAÇÃO ENQUANTO POLÍTICA PÚBLICA}

Entende-se por políticas públicas o conjunto de programas, ações e atividades desenvolvidas pelo Estado diretamente ou indiretamente, com a participação de entes públicos ou privados, que visam assegurar determinado direito de cidadania, de forma difusa ou para determinado seguimento social, cultural, étnico ou econômico ${ }^{15}$. Assim, as políticas públicas irão corresponder a direitos assegurados constitucionalmente ou que se afirmam graças ao reconhecimento por parte da sociedade. Deste modo podemos entendê-las como sendo um conjunto de ações políticas voltadas ao atendimento das demandas sociais.

A Constituição Federal assegura em seu artigo $5^{\circ}$, inciso $\mathrm{XXXV}^{16}$ o direito ao acesso à justiça. Como tal, caberá ao judiciário apreciar qualquer demanda que seja levada ao seu conhecimento. Atrelado a isto temos o princípio da duração razoável do processo, instituído com status de princípio fundamental pelo inciso LXXVIII $^{17}$ do mesmo texto normativo acima referenciado, cabendo ao Poder Judiciário a observância da eficiência operacional, acesso à justiça e responsabilidade social, nos moldes da Resolução n. $70^{18}$ do Conselho Nacional de Justiça - CNJ .

\footnotetext{
15 Disponível em: <http://www.meioambiente.pr.gov.br/arquivos/File/coea/pncpr/O_que_sao_PoliticasPublicas.pdf>

${ }^{16} \mathrm{CF} / 88$ : art. $5^{\circ}, \mathrm{XXXV}$ - a lei não excluirá da apreciação do Poder Judiciário lesão ou ameaça a direito.

${ }^{17} \mathrm{CF} / 88$ : art. $5^{\circ}$, LXXVIII - a todos, no âmbito do judicial e administrativo, são assegurados a razoável duração do processo e os meios que garantam a celeridade de sua tramitação.

${ }^{18}$ Disponível em <http://www.cnj.jus.br/gestao-e-planejamento/gestao-e-planejamento-do-judiciario/resolucao-n-70>
} 
Em contrapartida a este ideal de eficiência jurisdicional nos deparamos com um judiciário que vem sendo cada vez mais requisitado a dispor sobre os mais variados contextos conflituosos. Um judiciário sobrecarregado, chamado a todo o momento para posicionar-se sobre demandas que poderiam facilmente ser resolvidas por via administrativa, mas que são postas sob sua tutela em face de um costume social de fazer do jurídico o primeiro meio a ser procurado para solucionar uma demanda. Esquece-se que o Judiciário é um órgão de exceção e como tal só deveria ser utilizado quando as demais instâncias para a resolução do conflito falharem. O excesso de demandas o incapacita de atender aos que a ele recorrem de modo a estar em conformidade com os princípios anteriormente citados.

Em face de toda essa controvérsia entre o ideal jurisdicional e sua realidade quanto a eficácia da prestação de seus serviços, Ana Carolina Ghisleni ${ }^{19}$ entende que se faz por necessária a consolidação de uma política pública permanente de incentivo e aperfeiçoamento dos mecanismos consensuais de solução de litígios, sendo a mediação um deles, como instrumento efetivo de pacificação social.

Neste ínterim, coube ao CNJ por meio da Resolução n. $125^{20}$, de novembro de 2010, a qual determinou que deverá os órgãos judiciários oferecer mecanismos de soluções de conflitos, bem como prestar atendimento e orientação ao cidadão. A Resolução considera que a mediação, juntamente

${ }^{19}$ GHISLENI, Ana Carolina. A mediação enquanto política pública no tratamento de conflitos: a teoria e a prática em ace da análise do projeto existente em Santa Cruz do Sul - cap VII. In: Mediação enquanto política pública: o conflito, a crise de jurisdição e as práticas mediativas. Santa Cruz do Sul: EdUNISC, 2012. 1. Ed. p. 200. Disponível em:

〈http://www.unisc.br/portal/upload/com_editora_livro/mediacao.pdf $>$. Acesso em fev. 2014.

${ }^{20}$ Disponível em < http://www.cnj.jus.br/atos-administrativos/atos-da-presidencia/323-resolucoes/12243-resolucao-no-125-de-29-de-novembro-de-2010> 
com a conciliação, é um instrumento efetivo de solução e prevenção de litígios, tendo que sua pratica, em alguns programas já implementados no país, reduziu a excessiva judicialização dos conflitos, prevendo, portanto, a mediação como política pública de tratamento adequado dos conflitos de interesse.

\section{A MEDIAÇÃO E O CÓDIGO DE PROCESSO CIVIL DE 2015}

\subsection{NORMAS QUE REGEM A MEDIAÇÃO}

O mediador deve pautar suas condutas em conformidade com determinadas diretrizes impostas ao instituto da mediação. Diretrizes estas que vão diferenciá-la dos demais meios de pacificação de conflitos e irão impedir que o mediador aja arbitrariamente ou de modo imparcial. O profissional da mediação deve sempre agir no intuito de encaminhar as partes ao encontro de uma solução que beneficie integralmente ambos os mediandos.

Para isso, a mediação utiliza-se de alguns princípios básicos que irão delimitar a conduta do mediador e direcioná-lo quanto aos seus meios de atuação no conflito. O CONIMA - Conselho Nacional das Instituições de Mediação e Arbitragem ${ }^{21}$ destaca os seguintes princípios: imparcialidade, diligência, competência, credibilidade e sigilo, tendo este último sido estudado no tópico das características da mediação.

Pela Imparcialidade, ao deparar-se com uma situação de conflito o mediador não pode se deixar envolver pessoalmente na questão conflituosa. Não pode tomar partido por uma das partes, muito menos agir em benefício de um em detrimento do outro. Na mediação não há favorecidos, nem uma parte certa ou errada, haverá apenas os conflitantes que como tal serão auxiliados por um terceiro imparcial no objetivo de terem por solucionado o problema que os afligem.

${ }^{21}$ CONIMA. Regulamento modelo mediação. Disponível em:

<http://www.conima.org.br/regula_modmed>. acesso em mar 2014 
Para Rozane Cachapuz ${ }^{22}$, a imparcialidade será uma das principais características do mediador. Dirá respeito à prerrogativa de não se deixar envolver por valores pessoais que possam desviá-lo de sua real intenção que é garantir que os conflitantes alcancem um acordo benéfico para ambos.

Na Diligência o mediador deve pautar pela boa execução de seus atos de modo que a mediação seja realizada de maneira eficaz e prudente. Por assim, o princípio da diligência está vinculado à necessidade de garantia de zelo e a segurança da boa qualidade do processo de mediação.

Gustavo Crivari ${ }^{23}$ menciona que o melhor mediador não é aquele que possui índices significativos de acordos obtidos, mas sim aquele que permite que os participantes da mediação sintam-se significativamente mais felizes. Ou seja, o autor faz-se por compreender que um mediador diligente será aquele que melhor desempenhar o seu trabalho, não em um índice quantitativo, mas sim qualitativo.

Diante de todas as expectativas geradas pelo papel que deve ser exercido pelo mediador quando da mediação, não haveria dúvidas que o exercício de sua atividade irá requerer uma capacidade daquele que a desempenha.

Nesse contexto de capacidade é que se encontra pautado o princípio da competência. Para o CONIMA ${ }^{24}$, a competência está na capacidade de efetivamente mediar a controvérsia existente, devendo o mediador somente aceitar a tarefa quando tiver certeza de que possui as qualificações necessárias para satisfazer as expectativas das partes.

A Credibilidade está relacionada a capacidade do mediador de se fazer confiante, ele deve garantir a confiabilidade de seus serviços, transmitir segurança aos conflitantes. Paul Paclot ${ }^{25}$ afirma que:

${ }^{22}$ CACHAPUZ, Rozane da Rosa. Mediação nos conflitos \& direito de família. Curitiba: Juruá, 2003. p. 36.

${ }^{23}$ CRIVARI, Gustavo. A mediação como artifício dirimente do traumático processo de dissolução familiar. Revista jurídica da Unifil, Londrina, ano. 1, n.1, 2004. Disponível em: <http://web.unifil.br/docs/juridica/01/Revista\%20Juridica_01-15.pdf>. Acesso em mar. 2014.

${ }^{24}$ CONIMA. Regulamento modelo mediação. Disponível em:

<http://www.conima.org.br/regula_modmed>. acesso em mar 2014

${ }^{25}$ PACLOT, Paul. Conferência sobre mediação. apud CACHAPUZ, Rozane da Rosa. Mediação nos conflitos \& direito de família. Curitiba: Juruá, 2003. p. 37. 
O mediador não deve jamais esquecer que só detém seu poder senão graças à confiança que as partes depositaram nele e se assegurar de que nada, nem mesmo o conhecimento que as partes tenham tomado pela exteriorização de suas investigações seja suscetível de abalá-la.

Assim, para que o mediador esteja apto a cumprir o papel que por ele deve ser exercido, este deverá possuir uma postura que faça com que as partes quebrem as barreiras da desconfiança oriunda do desgaste emocional proveniente do conflito ainda não solucionado.

O novo CPC é claro ao trazer em seu texto normativo a exposição de alguns destes e mais outros princípios que deverão ser seguidos pelo Mediador durante a execução de sua atividade ${ }^{26}$.

\subsection{PRINCIPAIS INOVAÇÕES TRAZIDAS PELO NOVO CPC}

O texto do Novo Código de Processo Civil traz em seu corpo um destaque especial à Mediação e Conciliação, prevendo e disciplinado sua aplicação em diversos momentos. É o que denominamos de Sistema Multiportas, que é formado por um complexo de processos dentre os quais, o processo judicial, a mediação, a arbitragem, a conciliação, entre outros.

\footnotetext{
${ }^{26}$ Art. 166. A conciliação e a mediação são informadas pelos princípios da independência, da imparcialidade, da autonomia da vontade, da confidencialidade, da oralidade, da informalidade e da decisão informada.

$\S 1$ o A confidencialidade estende-se a todas as informações produzidas no curso do procedimento, cujo teor não poderá ser utilizado para fim diverso daquele previsto por expressa deliberação das partes.

$\S 20$ Em razão do dever de sigilo, inerente às suas funções, o conciliador e o mediador, assim como os membros de suas equipes, não poderão divulgar ou depor acerca de fatos ou elementos oriundos da conciliação ou da mediação.

$\S 30$ Admite-se a aplicação de técnicas negociais, com o objetivo de proporcionar ambiente favorável à autocomposição.

$\S 4$ o A mediação e a conciliação serão regidas conforme a livre autonomia dos interessados, inclusive no que diz respeito à definição das regras procedimentais.
} 
Vejamos, cada processo possui características especificas, o Sistema Multiportas busca pegar essas características intrínsecas de cada processo e utilizá-la para conseguir resoluções mais eficazes e, desta forma, reduzir as ineficiências do sistema processual puro, visto que a disputa será endereçada para o melhor meio de solução de conflito que se adeque ao caso concreto de acordo com suas peculiaridades.

A doutrina aponta como uma das principais mudanças trazidas pelo novo CPC, no que corresponde à Mediação, a regulamentação das Câmaras de Mediação e Conciliação que ficará a cargo dos Tribunais de Justiça de cada Estado juntamente com Conselho Nacional de Justiça - CNJ.

Cada Câmara de Mediação e Conciliação terá a responsabilidade de informar ao respectivo Tribunal de Justiça todos os processos que estejam em trâmite ou que já tenham sido solucionados.

Uma nova mudança seria a introdução dos Mediadores e Conciliadores no rol dos auxiliares da justiça ${ }^{27}$. Essa inovação se deu em razão da recomendação ${ }^{\circ} 50$ de 08 de maio de 2014 do $\mathrm{CNJ}$ onde esta recomenda aos Tribunais de Justiça e Tribunais Regionais Federais o incentivo ao desenvolvimento de seus Núcleos Permanentes de Métodos Consensuais de Solução de Conflitos.

Dentre outras inovações teremos: a priorização da Autocomposição, ou seja, se a petição inicial preencher todos os seus requisitos, será designada uma audiência de Conciliação ou de Mediação. Os mediadores judiciais e os conciliadores serão cadastrados em um cadastro nacional e em um cadastro do Tribunal de Justiça ou Tribunal Regional Federal, que manterá o registro destes profissionais, inclusive de modo a indicar sua área de atuação.

Outra inovação do Novo CPC é a previsão de remuneração para os conciliadores e mediadores ${ }^{28}$, salvo se a atividade for desenvolvida como trabalho voluntário. Da mesma forma o texto legal prevê que o advogado que esteja atuando na autocomposição terá seus honorários pagos

${ }^{27}$ Art. 149. São auxiliares da Justiça, além de outros cujas atribuições sejam determinadas pelas normas de organização judiciária, o escrivão, o chefe de secretaria, o oficial de justiça, o perito, o depositário, o administrador, o intérprete, o tradutor, o mediador, o conciliador judicial, o partidor, o distribuidor, o contabilista e o regulador de avarias.

${ }^{28}$ Art. 169. Ressalvada a hipótese do art. 167, § 6o, o conciliador e o mediador receberão pelo seu trabalho remuneração prevista em tabela fixada pelo tribunal, conforme parâmetros estabelecidos pelo Conselho Nacional de Justiça. 
integralmente caso o processo seja solucionado por via extrajudicial de solução de litígios

Por fim, os advogados que atuem como mediador ou conciliador estarão impedidos de exercerem a advocacia no Juízo em que desemprenhem a função de autocomposição do conflito.

\subsection{DA AUDIÊNCIA DE CONCILIAÇÃO E MEDIAÇÃO}

Para o prosseguimento do trâmite do processo comum no novo Código de Processo Civil, requer-se que a partir do momento em que o réu for citado para integrar a lide processual, ele também será intimado para comparecer a uma audiência de conciliação e mediação ${ }^{29}$.

A audiência não tem por objetivo a produção de provas, objetiva apenas a obtenção de um acordo entre as partes, que se alcançado irá pôr fim ao litígio, senão, segue-se o trâmite processual e a consequente intimação do réu para apresentar contestação.

Entre a citação do réu e a audiência deve existir um prazo mínimo de 20 (vinte) dias, já entre a intimação do autor e a realização da audiência o interstício mínimo deve ser de 30 (trinta) dias, devendo o autor ser intimado na pessoa de seu advogado, conforme dispõe o texto legal do novo Código de Processo Civil.

A realização de um procedimento mediatório ou conciliatório dependerá da existência ou não de uma relação jurídica entre as partes. Caso as partes já possuam uma relação jurídica anterior ao conflito, estaremos diante de uma hipótese de mediação, senão será realizada uma conciliação. Contudo, parte da doutrina, em especial Sérgio Ricardo ${ }^{30}$, defende a tese de que a mediação é apenas um meio para se alcançar a conciliação. Assim

${ }^{29} \mathrm{CPC} / 2015$ - Art. 334. Se a petição inicial preencher os requisitos essenciais e não for o caso de improcedência liminar do pedido, o juiz designará audiência de conciliação ou de mediação com antecedência mínima de 30 (trinta) dias, devendo ser citado o réu com pelo menos 20 (vinte) dias de antecedência.

${ }^{30}$ SILVA, Sérgio Ricardo Desiderio da. A mediação como método de resolução de conflitos relacionados à gestão de recursos hídricos no Distrito Federal. In:Ấmbito Jurídico, Rio Grande, XII, n. 66, jul 2009. Disponível em:

<http://www.ambitojuridico.com.br/site/index.php?n_link=revista_artigos_leitura\&artigo_id=6429>. Acesso em mar 2014. 
a mediação seria o método de resolução do conflito e a conciliação seria a finalidade daquele.

Cabe ainda esclarecer que nem todos os conflitos serão suscetíveis a um processo de autocomposição. O CPC em seu artigo $334, \S 4^{\text {o31 }}$ elenca duas hipóteses em que não ocorrerá a audiência: 1. Quando o objeto do processo não admitir autocomposição; 2. Quando as partes, expressamente, manifestarem desinteresse no acordo. Nesta segunda hipótese a não realização da audiência dependerá de uma manifestação da parte autora quando da propositura da ação, manifestando o desinteresse na composição consensual já na sua petição inicial.

Contudo, não basta a manifestação da parte autora, é preciso que a parte ré também se manifeste de forma contrária a realização da audiência, o fazendo por meio de petição nos autos onde declare de forma expressa o mútuo desinteresse na composição consensual do conflito. Caso não haja a declaração mútua de ambas as partes a audiência será realizada independente da vontade unilateral do autor ou do réu e o não comparecimento de uma das partes corresponderá a ato atentatório à dignidade da Justiça, suscetível à sanção ${ }^{32}$.

As audiências ou sessões de conciliação e mediação serão realizadas nos Centros de Solução de Conflitos, que deverão ser obrigatoriamente criados pelos Tribunais ${ }^{33}$. Fredie Didier ${ }^{34}$ nos explicita que a realização das sessões e audiências de conciliação ou mediação no próprio juízo onde tramita o processo é uma exceção, devendo, em regra, essa competência ser desempenhada pelos Centros de Solução de Conflitos.

${ }^{31} \mathrm{CPC} / 2015$ - Art. $334, \S 4^{\circ}$. A audiência não será realizada: I - se ambas as partes manifestarem, expressamente, desinteresse na composição consensual; II - quando não se admitir a autocomposição.

${ }^{32}$ Art. $334, \S 8^{\circ}$. O não comparecimento injustificado do autor ou do réu à audiência de conciliação é considerado ato atentatório à dignidade da justiça e será sancionado com multa de até dois por cento da vantagem econômica pretendida ou do valor da causa, revertida em favor da União ou do Estado.

${ }^{33} \mathrm{CPC} / 2015$ - Art. 165. Os tribunais criarão centros judiciários de solução consensual de conflitos, responsáveis pela realização de sessões e audiências de conciliação e mediação e pelo desenvolvimento de programas destinados a auxiliar, orientar e estimular a autocomposição.

${ }^{34}$ Didier Jr., Fredie. Curso de Direito Processual Civil - volume 1. Salvador: Jus Podivm, 2015. p. 279. 
Cada Centro de Solução de Conflitos deverá conter um juiz coordenador que será responsável pela sua administração e pela supervisão dos serviços desempenhados pelos conciliadores ou mediadores ${ }^{35}$.

\section{CONSIDERAÇÕES FINAIS}

Em face do presente trabalho e do evidente enfoque do Novo CPC sobre o tema, conseguimos caracterizar a mediação. Entendemos que esta tem por finalidade buscar a raiz desencadeadora do conflito, sendo exercida por um terceiro chamado pelas partes conflitantes para ajudá-los a caminhar em busca da resolução do impasse.

A palavra-chave da mediação será o reestabelecimento da comunicação, esta será de primordial importância para a formulação do acordo entre os litigantes. O instituto será responsável por retomar o diálogo entre aqueles que não conseguiam se resolver e ao mesmo tempo reaproximálos, restabelecendo assim, os laços que uma vez foram rompidos, em razão disso a mediação será aconselhada nos casos em que já exista uma relação jurídica entre as partes, antes mesmo do litígio.

Viu-se, também, que os conflitantes serão os protagonistas para a estruturação do acordo, ao contrário do que ocorre em outros métodos alternativos de resolução de conflitos, o mediador não irá impor nem propor um acordo a ser aceito, mas apenas, auxiliará as partes para que elas encontrem uma solução que as beneficiem igualmente, sendo selado por acordo firmado, concretizando assim a natureza contratual da mediação.

Assim, ao que pese as características e os meios utilizados pela mediação para a solução dos conflitos que a ela são impostas a resolução, concluímos que este será um método de grande eficácia para a resolução dos litígios, isto porque esta proporciona uma conclusão do impasse de

\footnotetext{
${ }^{35}$ Resolução 125 do CNJ - Art. $9^{\circ}$ Os Centros contarão com 1 (um) juiz coordenador e, se necessário, com 1 (um) adjunto, aos quais caberão a sua administração e a homologação de acordos, bem como a supervisão do serviço de conciliadores e mediadores. Salvo disposição diversa em regramento local, os magistrados da Justiça Estadual e da Justiça Federal serão designados pelo Presidente de cada tribunal dentre aqueles que realizaram treinamento segundo o modelo estabelecido pelo CNJ, conforme Anexo I desta Resolução. (Redação dada pela Emenda $n^{\circ}$ 2, de 08.03.16)
} 
forma mais célere, eficiente, econômica, com um menor desgaste emocional, haja vista sua capacidade de ressocializar as partes.

Assim os resultados da mediação serão sempre positivos, independente dos mediandos terem ou não chegado a um acordo, já que esta pressupõe o restabelecimento do diálogo e assim, o envolvimento e o enfrentamento das pessoas frente aos seus problemas. A mediação busca acima de tudo tratar o lado emocional do conflito resolve-lo na origem, evitando assim um novo enfrentamento de uma mesma questão, fazendo com que os conflitantes se reconheçam como pessoas dotadas de direitos e deveres em pé de igualdade enquanto pessoa humana.

\section{REFERÊNCIAS BIBLIOGRÁFICAS}

AGUIAR, Leonardo Pessoa. A mediação no âmbito familiar. In: JurisWay, enviando em 05 jun 2010. Disponível em: $\langle$ http://www.jurisway.org.br/v2/dha ll.asp?id_dh=4121 >.

CACHAPUZ, Rozane da Rosa. Mediação nos conflitos \& direito de família. Curitiba: Juruá, 2003.

CENCI, Andreia Katia. Mediação familiar: um método de facilitação para resolução de conflitos sem a demora dos judiciários, com benefícios para ambas às partes. Disponível em: <http://www.egov.ufsc.br/portal/conteudo /media\%C3\%A7\%C3\%A3o-familiar-um-m\%C3\%A9todo-defacilita\%C3\%A7\%C3\% A 3o-para-resolu\%C3\%A7\%C 3\%A3o-deconflitos-sem-demora-dos-judic>.

CRIVARI, Gustavo. A mediação como artifício dirimente do traumático processo de dissolução familiar. Revista jurídica da Unifil, Londrina, ano. 1, n.1, 2004. Disponível em: <http://web.unifil.br/docs/juridica/01/Revista\%20Juridica_0115.pdf $>$.

CONIMA. Regulamento modelo mediação. Disponível em: $\langle$ http://www.conima. org.br/regula_modmed $>$.

GALVÃO, Cibele Ramos. A mediação como instrumento consensual nos conflitos familiares. In: FEMPAR, Curitiba, publicado em: 19 ago 2010.

Disponível em:<http://www.femparpr.org.br/artigos/upload_artigos/cibele\%20 ramos\%20galvao.pdf $>$. 
GRUSPUN, Hain. Mediação familiar: o mediador e a separação de casais com filhos. São Paulo: Ltr, 2000.

MIRANDA, Ana Karine Pessoa Cavalcante. Estudos sobre a efetivação do direito na atualidade - A cidadania em debate - Mediação de conflitos. ARTIGO: A mediação de conflitos como instrumento de acesso ã justiça, inclusão social e pacificação, p.8.

NASCIMENTO, Joelma Gomes do. Mediação: meio alternativo para solução de conflitos. In:Âmbito Jurídico, Rio Grande, XIV, n. 84, jan 2011.

Disponível em:<http://www.ambitojuridico,com.br/site/index.php?n_link=revi sta_artigos_leitura\&artigo_id=8921>.

PRUDENTE, Neemias Moretti. A mediação e os conflitos familiares. In: Âmbito Jurídico, Rio Grande, XI, n. 52, abr 2008. Disponível em: $<$ http://www.ambito-

juridico.com.br/site/index.php?n_link=revista_artigos_leitura\&arti go_id=2536>.

Resolução do CNJ no 125 de 29 de Novembro de 2010. Disponível em: $<$ http://www.cnj.jus.br/atos-administrativos/atos-dapresidencia/323resolucoes/12 243-resolucao-no-125-de-29-denovembro-de-2010>.

SILVA, Sérgio Ricardo Desiderio da. A mediação como método de resolução de conflitos relacionados à gestão de recursos hídricos no Distrito Federal. In:Âmbito Jurídico, Rio Grande, XII, n. 66, jul $2009 . \quad$ Disponível em: <http://www.ambitojuridico.com.br/site/index.php?n_link=revi sta_artigos_leitura\&artigo_id=6429>.

MORI, Amaury Haruo. Princípios gerais aplicáveis ao processo de mediação e conciliação. In. Revista do Tribunal do Trabalho da 9. Região, 1976, v. 34, n. 63, p. 117-156, jul./dez., 2009.

DIDIER JR., Fredie. Curso de Direito Processual Civil - volume 1. Salvador: Jus Podivm, 2015. $17^{\mathrm{a}} \mathrm{ed}$. 